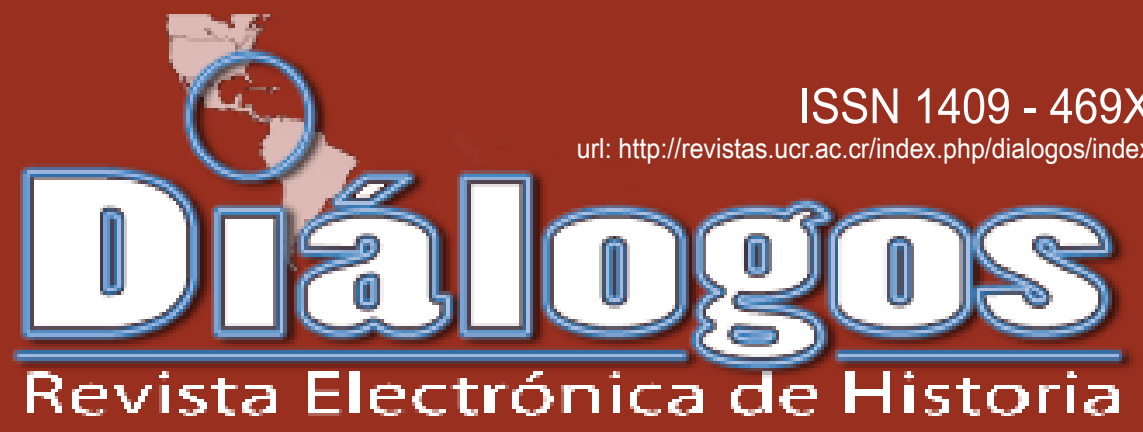

Escuela de Historia. Universidad de Costa Rica Volumen 14 especial en homenaje a Victor Hugo Acuña. Octubre 2013

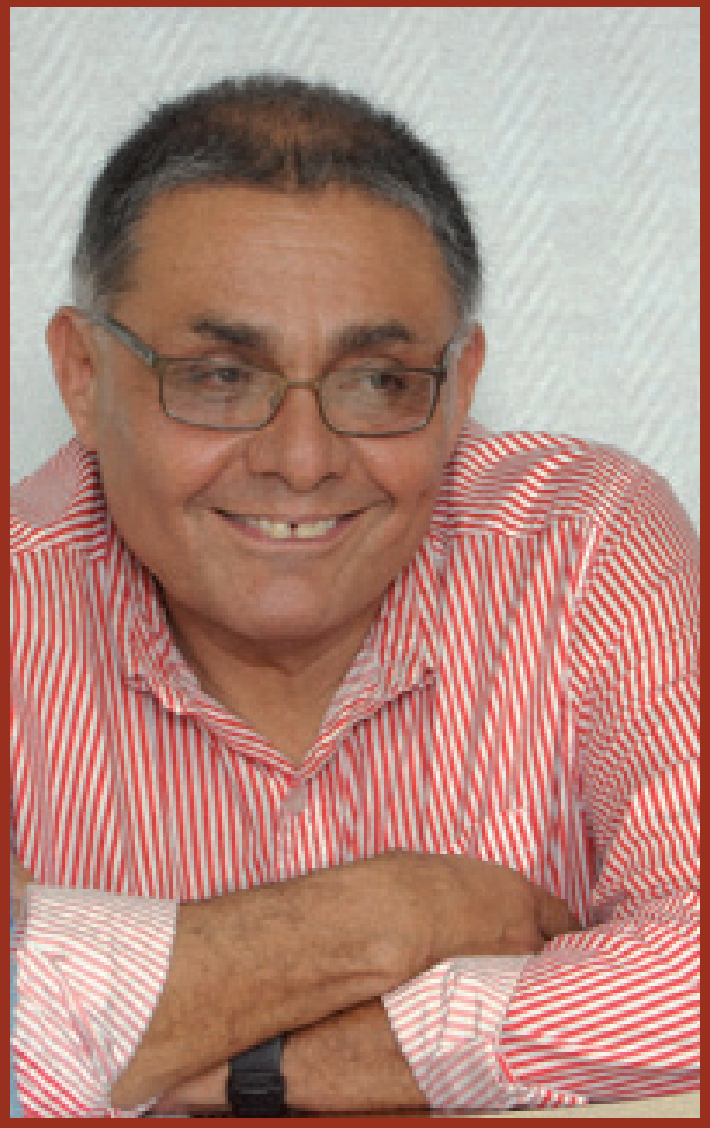

Director de la Revista: Dr. Juan José Marín Hernández juan.marinhernandez@ucr.ac.cr

Editor académico: Dr. Ronny Viales Hurtado - ronny.viales@ucr.ac.cr Editor técnico: M.Sc. Marcela Quirós G. - marcela.quiros@ucr.ac.cr 



\section{Miembros del Consejo Editorial:}

Dr. Juan José Marín Hernández, Catedrático. Director del Centro de Investigaciones Históricas de América Central. Universidad de Costa Rica. Costa Rica. juan. marin@ucr.ac.cr

Dr. Ronny Viales Hurtado. Catedrático. Historia Económica y Social. Universidad de Costa Rica. Director de la Escuela de Historia. Costa Rica. ronny. viales@ucr.ac.cr

Dr. David Díaz Arias: Catedrático. Historia Política, Director del posgrado de Historia y Docente de la Escuela de Historia, Universidad de Costa Rica, Costa Rica.david.diaz@ucr.ac.cr

MSc. Francisco Enríquez. Historia Social. Universidad de Costa Rica. Costa Rica. francisco.enriquez@ucr. ac.cr

Dra. Ana María Botey. Historia de los movimientos sociales. Universidad de Costa Rica. Costa Rica. abotey@gmail.com

\section{Miembros del Consejo Asesor Internacional:}

Dr. José Cal Montoya. Universidad de San Carlos de Guatemala. Guatemala. jecalm@correo.url.edu.gt

Dr. Juan Manuel Palacio. Universidad Nacional de San Martín. Argentina.jpalacio@unsam.edu.ar

Dr. Eduardo Rey. Universidad de Santiago de Compostela. España. ereyt@usc.es

Dr. Heriberto Cairo Carou. Departamento de Ciencia Política y de la Administración III Universidad Complutense de Madrid. España. hcairoca@cps.ucm.es

Dra. Rosa de la Fuente. Departamento de Ciencia Política y de la Administración III Universidad Complutense de Madrid. España. rdelafuente@cps. ucm.es

Dr. Javier Franzé. Departamento de Ciencia Política y de la Administración III Universidad Complutense de Madrid. España. javier.franze@cps.ucm.es

Dr. Jaime Preciado Coronado Departamento de Estudios Ibéricos y Latinoamericanos. Universidad de Guadalajara. México. japreco@hotmail.com
Dr. Gerónimo de Sierra. Vicerrector de la Universidade Federal da Integração Latino-Americana (UNILA) y Departamento de Sociología, Facultad de Ciencias Sociales de la Universidad de la República. Uruguay. geronimo@fcs.edu.uy

Dr. Antonio Palazuelos. Departamento de Ciencia Política y de la Administración III - Universidad Complutense de Madrid. España. palazuelosa@cps. ucm.es

Dr. Werner Mackenbach. Universidad Potsdam. Alemania. werner.mackenbach@uni-potsdam.de

Dr. Guillermo Castro. Ciudad del Saber Panamá. Panamá. gcastro@cdspanama.org

Dra. Natalia Milanesio. University of Houston. Estados Unidos.nmilane2@Central.UH.EDU

Dr. Ricardo González Leandri. Consejo Superior de Investigaciones Científicas - España. España. rgleandri@gmail.com

Dra. Mayra Espina. Centro de Estudios Psicológicos y Sociológicos, La Habana. Cuba.mjdcips@ceniai.inf.cu

Dra. Montserrat Llonch. Departamento de Economía e Historia Económica Universidad Autónoma de Barcelona. España.montserrat.llonch@uab.es

Dra. Estela Grassi. Universidad de Buenos Aires. Argentina. estelagrassi@gmail.com

Dra. Yolanda Blasco. Universidad de Barcelona. España. yolandablasco@ub.edu

Dr. Alfredo Falero. Departamento de Sociología. Universidad de la República. Uruguay. alfredof@adinet. com.uy

\section{Portada:}

Fotografía de Anel Kenjekeeva, Oficina de Divulgación Universidad de Costa Rica, publicada en http://www. ucr.ac.cr/noticias/2012/09/13/escuela-de-historia-rindehomenaje-a-victor-hugo-acuna.html

\section{Equipo Técnico Editorial:}

Editora Técnica: M.Sc. Marcela Quirós Garita.marcela. quiros@ucr.ac.cr Diagramación: Cindy Chaves Uribe Asistentes: Pablo Hurtado GranadosMaureen Méndez Montero 
"Diálogos Revista Electrónica de Historia" se publica desde octubre de 1999.

\section{Diálogos está en los siguientes repositorios:}

Dialnet

http://dialnet.unirioja.es/servlet/

revista?tipo_busqueda=CODIGO\&clave_revista $=3325$

Latindex

http://www.latindex.unam.mx/larga.php?opcion=1\&folio=12995;

\section{UCRindex}

http://www.revistas.ucr.ac.cr/

\section{Scielo}

http://www.scielo.cl/

\section{eRevistas}

http://www.erevistas.csic.es/

\section{REDALYC}

http://redalyc.uaemex.mx/src/inicio/FrmBusRevs2.jsp?iEdoRev=2\&cvepai=11;

\section{LANIC}

http://lanic.utexas.edu/la/ca/cr/indexesp.html

Repositorio de Revistas Universidad de Costa Rica http://www.latindex.ucr.ac.cr/

Directorio y recolector de recursos digitales del

Ministerio de Cultura de España

http://roai.mcu.es/es/inicio/inicio.cmd

DOAJ Directory of open access \& Hybrid journals

http://www.doaj.org/doaj?func=byTitle\&hybrid=1\&query=D

Biblioteca de Georgetown

http://library.georgetown.edu/newjour/d/msg02735.html

Asociación para el Fomento de los Estudios Históricos en Centroamérica

http://afehc. apinc.org/index.php?action=fi_aff\&id=1774

Universidad de Saskatchewan, Canadá

https://library.usask.ca/ejournals/view/1000000000397982

\section{Monografias}

http://www.monografias.com/Links/Historia/more12.shtml

\section{Hispanianova}

http://hispanianova.rediris.es/general/enlaces/hn0708.htm

Universidad del Norte, Colombia

http://www.uninorte.edu.co/publicaciones/memorias/enlaces.htm

Universidad Autónoma de Barcelona

http://seneca.uab.es/historia/hn0708.htm

Repositorio Invenia - Gestión del Conocimiento http://www.invenia.es/oai:dialnet.unirioja.es:ART0000086144

\section{Enlace Académico}

http://www.enlaceacademico.org/biblioteca/

revistas-en-formato-digital-centroamerica/

\section{Electronic Resources}

http://sunzi1.lib.hku.hk/ER/detail/hkul/3987318

Revistas académicas en texto completo http://web.prw.net/ vtorres/
Diálogos se anuncia en las siguientes instituciones y sitios académicos:

\section{Maestroteca}

http://www.maestroteca.com/detail/553/dialogos-revista-electronica-de-historia.htm

Biblioteca de Georgetown

http://library.georgetown.edu/newjour/d/msg02735.html

Asociación para el Fomento de los Estudios Históricos en Centroamérica

http://afehc. apinc.org/index.php?action=fi_aff\&id=1774

Universidad de Saskatchewan, Canadá

https://library.usask.ca/ejournals/view/1000000000397982

\section{Monografias}

http://www.monografias.com/Links/Historia/more12.shtml

\section{Hispanianova}

http://hispanianova.rediris.es/general/enlaces/hn0708.htm

Universidad del Norte, Colombia

http://www.uninorte.edu.co/publicaciones/memorias/enlaces.html

Universidad Autónoma de Barcelona

http://seneca.uab.es/historia/hn0708.htm

Repositorio Invenia - Gestión del Conocimiento

http://www.invenia.es/oai:dialnet.unirioja.es:ART0000086144

\section{Enlace Académico}

http://www.enlaceacademico.org/biblioteca

revistas-en-formato-digital-centroamerica/

\section{Electronic Resources}

http://sunzi1.lib.hku.hk/ER/detail/hkul/3987318

Revistas académicas en texto completo

http://web.prw.net/ vtorres/

La revista electrónica Diálogos es financiada por Vicerrectoría de Investigación de la Universidad de Costa Rica
Dialnet - eRevistas

- UCRindex - Latindex -

REDALYC - DOJAC - Directorio

y recolector de recursos

digitales del Ministerio de

Cultura de España

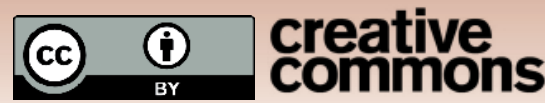





\title{
HISTORIA DE LOS TRABAJADORES COSTARRICENSES: EL APORTE DE VÍCTOR HUGO ACUÑA ORTEGA
}

HISTORY OF COSTA RICAN WORKERS: VÍCTOR HUGO ACUÑA ORTEGA'S STUDIES

Francisco Javier Rojas Sandoval

\author{
Palabras claves \\ Historiografía Social, Costa Rica.
}

\section{Keywords}

Social Historiogrpahy, Costa Rica.

Fecha de recepción: 17 de mayo, 2013 - Fecha de aceptación: 8 de agosto 2013

\section{Resumen}

Este trabajo aborda la producción historiográfica de Víctor Hugo Acuña y su impacto en la producción historiográfica de historiadores ligados a la historia social.

\begin{abstract}
This paper studies Víctor Hugo Acuña Ortega's historiography and its impact on Costa Rican social historians.
\end{abstract}





\section{HISTORIA DE LOS TRABAJADORES COSTARRICENSES: EL APORTE DE VÍCTOR HUGO ACUÑA ORTEGA}

Francisco Javier Rojas Sandoval

\section{INTRODUCCIÓN}

La historia de los de abajo y de los trabajadores en general constituye un rasgo distintivo de la llamada nueva historia la cual es heredera de los aportes teóricos de la historiografía marxista británica por rescatar del anonimato a los sectores subalternos los cuales habían sido encasillados por la historiografía tradicional bajo la categoría genérica de "pueblo" (Harvey, 1989, pp. 199-224).

El aporte de Acuña no solo debemos visualizarlo en términos de su producción historiográfica la cual indudablemente abrió nuevas perspectivas de análisis sino también en su contribución en la formación de una serie de historiadores que transitaron por la historia social bajo su guía.

Este artículo el cual constituye gran parte de la ponencia presentada en el homenaje organizado por el Posgrado Centroamericano en Historia, el Centro de Investigaciones Históricas de América Central y la Escuela de Historia hacia el Dr. Víctor Hugo Acuña Ortega por su gran trayectoria, su aporte a la historiografía costarricense y sobre todo su papel de maestro como formador de una serie de historiadores e historiadoras en el campo de la historia social aborda dos grandes ejes: una referida a la producción historiográfica y otra concerniente a su impacto en la producción historiográfica de historiadores ligados a la historia social.

El trabajo historiográfico del profesor Acuña en lo concerniente al estudio de los trabajadores se delimito en tres grandes aéreas: los trabajadores en el mundo cafetalero- un mundo que se había visualizado como exento de conflictividad social-, los trabajadores en el universo bananero y los trabajadores en el mundo urbano.

El aporte de Acuña no solo debemos visualizarlo en términos de la historia social al develarnos el proceso de formación histórica de las clases trabajadoras sino también en términos de la historia económica al analizar la génesis de capitalismo en Costa Rica y en términos de la historia política al establecer hipótesis sugerentes en torno a la génesis de nuestro sistema democrático.

\section{LOS TRABAJADORES EN EL MUNDO CAFETALERO}

En un trabajo de Acuña publicado en 1985 (Acuña, 1985: 181-205) advertía en forma acertada que su abordaje implicaba una toma de posición frente a visiones 
míticas defendidas por la historiografía tradicional y declarase partidario de una historia que rescatara el papel jugado por las clases subalternas en la conformación de nuestra sociedad.

El trabajo en mención rechazaba la visión mítica de un universo exento de conflicto social (González, 1994, p. 276) y plantea una hipótesis que va a ser retomada por el autor en distintos trabajos: el régimen democrático costarricense no constituye una graciosa concesión de la clase dominante sino que es resultado de la confrontación de clases sociales.

Con respecto al primer mito el autor planteaba en 1986 como en Costa Rica existía el arraigado prejuicio de que la economía cafetalera, a diferencia del mundo bananero, era un universo exento de contradicciones sociales en donde los hacendados eran paternales y los peones y campesinos eran pasivos y conformistas (Acuña, 1986, p. 113). ${ }^{1}$

Lo que más llamaba la atención del autor hacia mediados del decenio de 1980 era que los estudios emprendidos hasta ese momento sobre la economía cafetalera no se hubiesen ocupado de los conflictos sociales a pesar de que todos reconocían la naturaleza desigual de sus relaciones económicas.

La protesta social en el mundo cafetalero es caracterizada por el autor como un movimiento de clases medias rurales en donde si bien los cosecheros esporádicamente hicieron referencia al problema de los salarios de los peones, jamás fue esa su preocupación central (Acuña, 1986a, p. 118).

Acuña nos señala como los peones siempre estuvieron ausentes o, más silenciosos en las luchas sociales. Solo durante la crisis de 1930 frente al flagelo de la desocupación realizaran algunas acciones y aparecerán algunos sindicatos y huelgas en algunas fincas del sector oriental del Valle Central donde había grandes fincas cafetaleras.

Sus hipótesis en torno a la génesis del sistema democrático costarricense realmente resultan novedosas a nivel de las ciencias sociales; en particular de cómo nuestra democracia se forjó bajo el yunque de la lucha de clases. Con respecto a la conflictividad en el universo cafetalero Acuña Ortega nos describe por un lado como las relaciones de clase en la producción cafetalera son conflictivas pero al mismo tiempo nos recuerda como en ellas siempre se busca darle espacio a la conciliación y a la colaboración de clases (Morris, 1990, pp. 30-31). ${ }^{2}$

Acuña nos retrata como los productores cafetaleros en alianza con los beneficiadores opusieron gran resistencia a las Reformas Sociales de la década de 1940; en particular resistieron la aplicación del Código de Trabajo y de los salarios mínimos para los peones cafetaleros (Acuña, 1987, p. 145).

El autor establece una agenda de investigación, una guía metodológica para el estudio de un movimiento social: la agenda del conflicto, las demandas de los productores, tipos de lucha, formas organizativas y patrón de liderazgo, composición 
social y distribución geográfica del movimiento, conducta de los beneficiadores, el papel del Estado, los logros y fracasos y la ideología y conciencia social (). ${ }^{3}$

$\mathrm{Su}$ aporte metodológico heredero de la historiografía marxista británica servirá de orientación a una serie de historiadores e historiadoras en el estudio de los movimientos sociales emprendidos por los trabajadores costarricenses en su lucha contra el capital.

\section{LOS TRABAJADORES EN EL MUNDO BANANERO}

Acuña Ortega incursiona en el estudio del universo bananero y más específicamente en el mundo de la United Fruit Company en donde resalta la contradicción entre capital y trabajo lo cual se refleja en las ásperas condiciones de vida de los trabajadores bananeros. Ellos sabían mejor que nadie en que consistía tratar con la compañía; su alimento, su vestido, su vivienda y su salud mostraban crudamente lo injusto de esa relación (Acuña, 1984, p. 13). El autor nos retrata las condiciones de vida de estos trabajadores: los famosos "campamentos" de estos trabajadores eran una aglomeración de ranchos destartalados, insalubres, desprovistos de agua potable, letrinas y electricidad.

El interés del autor al abordar esta temática consiste precisamente en conocer este tipo de contradicciones del universo bananero a través del estudio del enfrentamiento más fuerte de los trabajadores con el capital monopolista durante la primera mitad del siglo XX: la gran huelga del atlántico de 1934.

En su interpretación de los factores que explican el estallido de la huelga de 1934 el autor establece tres factores los cuales se encuentran interrelacionados. En primer lugar el agudo deterioro de las ya de por sí, pésimas condiciones de vida de los peones, provocado por las medidas adoptadas por la United y los grandes finqueros para contrarrestar los efectos de la crisis económica; en segundo lugar, la experiencia de resistencia y lucha acumulada por los trabajadores bananeros y su disposición a la acción colectiva que expresaron en los meses previos a la huelga y finalmente, la labor política, organizativa y de conducción asumida por el Partido Comunista y en especial por el antiguo peón bananero Carlos Luis Fallas.

El trabajo en torno a la Huelga Bananera de 1934 tiene tres grandes aportes: en primer lugar constituye una obra de historia social diseñada no solo para el mundo académico sino para ser difundida a los sectores populares; en segundo lugar en la misma se retrata el costo social del gran imperio de banano evidenciado en las pésimas condiciones de trabajo y vida que sufrieron los trabajadores bananeros. Finalmente el autor propone una guía metodológica para abordar el análisis de una huelga: la agenda del conflicto, las demandas de los trabajadores, composición social del movimiento, las formas de organización, la distribución geográfica 
del movimiento, los líderes, el papel asumido por la United Fruit Company y el Estado y finalmente un balance del movimiento (). ${ }^{4}$

Acuña retrata como a diferencia de la UFCO, el Comité Central de la Huelga y el Partido Comunista buscaron permanentemente la negociación para resolver el conflicto y nunca adoptaron posiciones intransigentes (Acuña, 1984, p. 37) lo cual viene a ratificar la hipótesis planteada por el autor en torno a los orígenes de la democracia costarricense la cual se forja bajo el yunque de la lucha de clases en donde los trabajadores con su luchas han contribuido a tratar de forjar un mundo más igualitario en lo social logrando en algunos casos logros significativos y en otros sendas derrotas.

La huelga bananera de 1934 no representó una clara ruptura con la práctica del sistema político costarricense de resolver los conflictos más por la vía del consenso que apelando al uso indiscriminado de la fuerza; en sentido el autor señala que hay que reconocer que, aunque hubo represión, está no fue sangrienta como si ocurrió en la huelga bananera colombiana de 1928 y en la de Honduras en 1930 (Acuña, 1984, p. 47).

No obstante lo anterior Acuña Ortega nos recuerda el costo social que dicho movimiento social tuvo para los trabajadores en el mundo bananero al enfrentarse al imperio de la United Fruit Companny:

"no implica olvidar los sufrimientos de los trabajadores y los atropellos policiales a lo largo de la huelga." (Acuña, 1984, p. 47).

Estudiar a los de abajo no solo implica una labor académica de visibilizar a los olvidados y marginados aunque estos sean miopes y con un limitado "capital cultural" sino sobre todo determinar el costo social del capitalismo en sus distintas fases y comprometerse con los de abajo en la posibilidad de soñar construir un mundo más justo lo cual se inicia como señala Harvey Kaye (Harvey, 1989, p. 224) precisamente en educar a aquéllos para quienes la lucha es hoy una necesidad concreta con las experiencias históricas de aquellos otros para quienes la lucha fue una necesidad concreta ayer. Lo anterior constituye el legado del maestro Acuña Ortega.

\section{LOS TRABAJADORES EN EL MUNDO URBANO}

En un ciclo de mesas redondas titulado Historiografía Costarricense efectuado durante el primer semestre de 1985 en la Universidad de Costa Rica y posteriormente publicadas en un número especial de la Revista de Historia Carlos Hernández Rodríguez al realizar un balance de los trabajos historiográficos en historia social le asigna un peso de primera línea a la obra de Víctor Hugo Acuña la cual junto con el trabajo de Mario Oliva marcan una ruptura con la historiografía tradicional: 
"No sería sino en una segunda fase, inaugurada por la aparición de dos trabajos (Oliva, 1984; Acuña, 1986a), destacados por su carácter innovador, rigurosidad heurística y profundidad teórica, que tales insuficiencias empezarían a ser subsanadas, gracias a un nuevo enfoque más próximo a la explicación causal y al análisis de procesos, que a al teleología obrera y a la crónica de eventos." (Hernández, 1996, pp. 116-117).

El libro titulado Los orígenes de la clase obrera en Costa Rica: las huelgas de 1920 por la jornada de ocho horas (Acuña, 1986b, 88 p.) constituye un aporte fundamental en el análisis del proceso de formación histórica de la clase trabajadora costarricense.

Dicho trabajo constituye un hito en la historiografía de la historia social de Costa Rica pues en el mismo se plantean una serie de hipótesis novedosas en torno al origen de nuestro sistema democrático. De ahí que uno de los objetivos del trabajo sea precisamente señalar la influencia que han tenido los sectores populares en los proceso de conformación del sistema político costarricense lo cual le permitirá proponer algunas hipótesis para la comprensión crítica de la democracia en Costa Rica.

La obra a parte de su contribución al conocimiento histórico en torno al proceso de conformación de la clase trabajadora urbana costarricense posee el mérito de que fue escrito no solo para ser discutido por el mundo universitario sino que el mismo fue elaborado para que pudiera ser leído por dirigentes sindicales y comunales, por educadores populares, por estudiantes de secundaria y por el personal del magisterio nacional.

El estudio del proceso de formación de las clases trabajadoras es precedido por un estudio en torno al proceso de formación del capitalismo en el sector secundario de la economía para lo cual el autor nos lleva a conocer los diversos tipos de unidades productivas en los cuales laboraban dichos trabajadores desde el artesano aislado que recibe encargos de empresas manufactureras o comerciales, pasando por el taller artesanal hasta llegar a las manufacturas y las fábricas (Acuña, 1986b, pp. 9-13).

En este recorrido el autor nos retrata un cambio cualitativo nodal que sufren los trabajadores urbanos a inicios del siglo XX cual es el proceso de proletarización paulatina al cual se ven sometidos. Tal proceso tiene su correlato en las condiciones laborales y en los niveles de vida de los trabajadores.

Acuña Ortega nos describe las relaciones entre las clases trabajadoras urbanas y el Estado y las clases dominantes en la época dorada de la República Liberal en donde ni la violencia, ni la represión, ni la intransigencia, ni la marginación son los rasgos sobresalientes de esas relaciones; no obstante el mismo en una forma lúcida nos plantea la sugerente hipótesis de las excepciones en este patrón de relaciones de clase: los mineros y los obreros de plantaciones raramente recibieron ese trato 
suave y paternal, como lo atestigua la represión que padecieron los movimientos laborales que protagonizaron estos trabajadores en las dos primeras décadas del siglo XX (Acuña, 1986b, p. 23).

Fuera del Valle Central en la marejada huelguística de febrero de 1920, en los puertos y en las minas, el Gobierno envió destacamentos policiales que adoptaron aptitudes amenazantes e incluso represivas en contra de los trabajadores. Lo anterior viene a ratificar una hipótesis planteada por Acuña en el sentido de que el código de relaciones entre clases sociales fue distinto en las zonas periféricas y el Valle Central; en este pacto social indudablemente había ciudadanos de segunda clase.

Los orígenes de la clase obrera en Costa Rica: las huelgas de 1920 por la jornada de ocho horas nos abre una perspectiva de cómo abordar el estudio de las leyes: la génesis de las mismas hay que rastrearlas en última instancia, en los procesos de confrontación y negociación de los actores sociales como lo constata la aprobación de la ley número 100 del 9 de diciembre de 1920 sobre la jornada laboral de ocho horas.

El autor establece una reflexión sobre la génesis de la democracia costarricense visualizando el papel activo que han desempeñado las clases trabajadoras en la forja de nuestra estructura política y nuestro régimen social:

"la democracia costarricense es la resultante de la dirección hegemónica de las clases dominantes y de las presiones persistentes y crecientes de los sectores sociales subordinados. Nuestro régimen democrático es una síntesis de fuerzas sociales y es un proceso incesante de renegociación entre ellas." (Acuña, 1986b, p. 81).

El futuro de la democracia costarricense está en los trabajadores la cual debe forjarse bajo el yunque de la luchas de clases en donde si bien pueden negociar está negociación debe darse bajo el expediente de la lucha social. En este camino los intelectuales y académicos también deben de jugar un papel de primera línea no solo en el estudio de estos procesos sino en la concientización de los actores sociales a través de la memoria popular costarricense y de contribuir a sensibilizar a las organizaciones populares sobre la conveniencia de conocer y estudiar la historia de las clases trabajadoras costarricenses. En sentido resulta un imperativo ético emprender su estudio y posteriormente socializarlo con las clases subalternas.

Los trabajos de Acuña y muy particularmente su estudio sobre los zapateros (Acuña, 1988, pp. 223-244) marcaron en buena medida el rumbo para futuras investigaciones sobre sectores o ramos del mundo laboral al dimensionar la pervivencia de formas típicas de organización artesanal del trabajo y establecer su incidencia concreta sobre los modos de asociación y de lucha (Hernández, 1996. P. 120).

En dicho trabajo el autor intenta descubrir las relaciones que existen entre la vida cotidiana, las condiciones de trabajo y la organización sindical de estos trabajadores del calzado. El trabajo presenta el merito de rescatar de viva voz a los 
actores sociales a través de la autobiografía del Secretario General del Sindicato y de dos entrevistas colectivas realizadas con un grupo de antiguos militantes y dirigentes del Sindicato junto con seis historias de vida. Un notable mérito del trabajo desarrollado por Acuña lo constituye la participación misma del Sindicato y de jóvenes obreros del calzado con lo cual el conocimiento no solo se limito a ser abordado en el ámbito académico sino que trascendió hacia los sectores subalternos.

Acuña Ortega retrata magistralmente el mundo del taller en el cual laboraban los zapateros como un espacio de convivencia, un lugar de comunicación, un sitio en donde se tejía una red de relaciones interpersonales; no obstante, a pesar de formar una comunidad de hombres que tenían una gran libertad y autonomía en su existencia cotidiana el autor nos recuerda que su particular proceso de trabajo estaban enmarcadas en una relación salarial a destajo, es decir, en una relación de producción de explotación (Acuña, 1988, p. 231).

El autor plantea el estudio de la legislación laboral promulgada en 1943 desde una óptica distinta al visualizar el costo de está en el radicalismo de los zapateros. La legislación laboral abolió la sindicalización compulsiva, favoreció la desafiliación de grupos de trabajadores por razones ideológicas puesto que el Sindicato era de influencia comunista, o por el deseo de los operarios de eludir el pago de la cuota sindical.

Acuña establece como la mediación estatal al institucionalizar el conflicto (pues una vez establecida la legislación laboral el sindicato se vio obligado a canalizar los conflictos por medio de los tribunales) se minaron las bases de la conflictividad y de la combatividad obreras que habían sustentado la fortaleza e influencia del Sindicato (Acuña, 1988, pp. 237-240).

Lo anterior resulta vital para quienes ejercemos la profesión de historiador pues nos advierte que el estudio de la historia de los trabajadores debe evitar toda tentación evolucionista pues en esta historia, como en cualquier otra, hay avances y retrocesos, continuidad y ruptura.

\section{EL LEGADO DEL PROFESOR ACUÑA ORTEGA}

En el epílogo de La Huelga Bananera de 1934 (Acuña, 1984, p. 57) Víctor Hugo Acuña nos señala su objetivo de recordar la principal lucha social de aquellos años; no obstante nos recuerda que esa labor no estaba acabada ya que aún quedaba mucho por conocer. En ese sentido señalaba con cierta nostalgia el deseo de saber cómo se desarrollo día a día la huelga en cualquiera de las fincas o lo que pensó y sintió el dirigente de base o el trabajador común y corriente.

En una forma magistral el profesor Acuña concluye -hacia mediados del decenio de 1980- como el esfuerzo de rescate de la historia de las clases trabajadoras costarricenses apenas principiaba. En ese sentido aceptar que es mucho 
más lo que ignoramos que lo que sabemos es el mejor estímulo para que diversos sectores e individuos preocupados por el futuro de nuestro pueblo se sumen a esta tarea (Acuña, 1984, p. 57).

Tres décadas después lo planteado por Víctor Hugo Acuña sigue teniendo vigencia pues si bien se han logrado algunos avances en el conocimiento de las clases trabajadoras probablemente todavía sea más lo que desconocemos y resulta imperativo su estudio en un momento en donde los trabajadores de nuestro país ven violentados sus derechos laborales incluido el derecho mismo de tener un trabajo. Como nos lo recordaba Eric Hobsbawm en uno de sus últimos libros titulado Cómo cambiar el mundo:

"el mercado" no tiene respuesta al principal problema al que se enfrenta el siglo XXI: que el ilimitado crecimiento económico cada vez más altamente tecnológico en busca de beneficios insostenibles produce riqueza global, pero a costa de un factor de producción cada vez más prescindible, el trabajo humano" (Hobsbawm, 2011, p. 424).

La contradicción capital- trabajo sigue siendo una característica del patrón de acumulación de capital de las llamadas economías globalizadas con un imperativo aún más grave para los trabajadores que no solo ven violentados sus derechos laborales sino que tal y como apunta Hobsbawm el trabajo humano se ha vuelto más prescindible con lo cual los trabajadores y trabajadoras también han perdido el derecho a reproducirse no solo como fuerza de trabajo sino inclusive como seres humanos al verse imposibilitados de ganarse el pan de cada día. En 1995 Víctor Hugo Acuña en un debate en torno a la historiografía costarricense en el campo de la historia social señalaba lo siguiente:

"Los historiadores sociales, propiamente dichos, serían, en consecuencia, una especie en proceso de desaparición y sus actuales sobrevivientes serían aquellas personas que se dedican al estudio de las categorías ocupacionales y de la estructura social en su conjunto y al estudio de los movimientos sociales, en especial los de los trabajadores asalariados" (Acuña, 1996, p. 145).

Indudablemente los historiadores sociales que se dedican al estudio de los trabajadores y particularmente de los trabajadores urbanos a través del estudio de las categorías ocupacionales y de la acción colectiva de estos trabajadores han quedado relegados en el olvido en un momento en que se vuelve imperativo volver sobre ellos ante una sociedad excluyente en donde las desigualdades sociales son más extremas y donde lo único que poseen estos trabajadores es su "fuerza de trabajo" para tratar de sobrevivir ya no solo como trabajadores sino como seres humanos.

Al caracterizar la historia social en Costa Rica Acuña Ortega señalaba en forma acertada que esta presentaba un definitivo sabor lugareño y provinciano; lugareño porque básicamente lo que habíamos estudiado era el Valle Central y 
la ciudad de San José y provinciano porque poco nos habíamos ocupado de la investigación sobre los otros países centroamericanos. De ahí que alrededor de 1995 planteara que si había dos ramas que le debieran crecer al árbol de la historia social en nuestro país, estas debían ser la historia regional y la historia comparada (Acuña, 1996, p. 146).

Sin negar la importancia de desarrollar en nuestra historiografía la historia regional, labor que ha empezado a gestar el Centro de Investigaciones Históricas de América Central con su proyecto de historia regional y la utilización de la historia comparada, esencialmente con Centroamérica y América Latina para poder determinar la especificidad del caso costarricense resulta central desde nuestra perspectiva y el mismo constituye una tarea pendiente para quienes hemos cultivado la historia social realizar una obra de síntesis en torno a la historia social en general y de la clase trabajadora en particular.

En momentos en donde el poder de los empresarios se reparte el escaso botín de los fondos públicos resulta asimismo imperativo empezar a estudiar como señalaba Acuña a las clases altas y a las élites en general. Tal y como lo señalo hace ya casi dos décadas la opacidad de las clases dominantes es algo peligroso para toda sociedad democrática y lo es peor aún en los tiempos actuales en donde reinan la corrupción y la doble moral (Acuña, 1996, p. 149).

El legado del maestro Acuña para quienes fuimos sus discípulos en el campo de la historia social y de los trabajadores en particular no solo debemos visualizarlo en términos de su orientación teórica al llevarnos por los caminos trazados por la historiografía marxista británica en su proyecto histórico de rescatar a los anónimos y olvidados por la historiografía tradicional sino que nos inspiro para estudiar a quienes con su sudor y esfuerzo han construido nuestra sociedad en una forma que desconocíamos.

Debemos reconocer su esmero por organizar verdaderos talleres- tal y como lo hacían los trabajadores que estudiábamos- para discutir nuestros proyectos de tesis; recuerdo en particular uno auspiciado por CEDAL en Santa Barbará de Heredia en el año 1987 el cual nos dio la oportunidad no solo de conocer y compartir con historiadores de Centroamérica- Mario Posas y Arturo Taracena- y México sino también de discutir nuestras ideas.

$\mathrm{Su}$ predisposición a facilitarnos fuentes primarias demuestra no solo su compromiso académico sino su gran humanismo precisamente cuándo a quienes estudiamos constituían un contingente de trabajadores humildes.

El Dr. Acuña formo a un contingente de estudiosos en el campo de la historia social dirigiendo sus tesis de posgrado los cuales luego se insertarían mayoritariamente en una forma exitosa en el mundo académico: Virginia Mora Carvajal (Mora, 1998) con sus estudios sobre las obreras urbanas, José Manuel Cerdas (Cerdas, 1994) con su trabajo sobre los trabajadores urbanos en San José; Guillermo Rosabal 
(Rosabal, 1998) con su estudio sobre los panaderos y sus luchas; Carmen Murillo (Murillo, 1995) con su análisis en torno a los trabajadores ferroviarios y Francisco Javier Rojas (Rojas, 2004) con su trabajo sobre los carpinteros y ebanistas.

$\mathrm{Su}$ aporte debemos visualizarlo también en su contribución tendiente al rescate de la memoria popular costarricense y su innegable contribución a sensibilizar a nuestras organizaciones populares sobre la conveniencia de conocer y estudiar la historia de las clases trabajadoras costarricenses.

En ese sentido su trabajo de dar a conocer a la sociedad costarricense el aporte de los trabajadores en general con sus aciertos y errores y su contribución a la conformación de la democracia costarricense sin duda constituye un aporte central no solo para la academia y para las propias organizaciones sindicales sino para la sociedad en general en donde todavía hoy día los olvidados, los anónimos quizás todavía sueñen sino con un mundo utópico por lo menos con mundo en donde los frutos del trabajo pertenezcan única y exclusivamente a sus creadores.

Si bien ha nivel historiográfico se da el giro de una historia social a una historia cultural Paul Cartldge nos recuerda que seguimos necesitando la historia social como un tipo de historia o subespecie de historia, específicamente como una historia de clase, de opresión y explotación o en todo caso de pobreza (Cartledge, 2005, pp. 76-77). Lo anterior resulta vital en nuestra época en donde la relación capital-trabajo no solo sigue vigente sino impecable en términos de relaciones de explotación hacia quienes en última instancia producen la riqueza de las naciones.

\section{CITAS Y NOTAS}

1 La historiografía marxista británica -de la cual es heredera la producción académica de Acuñadebe recordarse que precisamente comenzaron a escribir para oponerse al paradigma imperante en los estudios históricos y sociales, que asumía no sólo que el orden social significaba la ausencia de conflicto social, en la forma de rebelión y oposición, sino que también indicaba la aceptación de la normativa.

2 Morris nos recuerda como históricamente las relaciones de clase son diversas las cuales incluyen relaciones de conflicto, de cooperación, deferencia y apatía. Véase: Morris, 1990: 30-31.

3 Los estudios de Acuña Ortega en torno a la conflictividad social en el universo cafetalero se basa en las aportaciones teóricas de E.P. Thompson y George Rude.

4 Dicha guía metodológica está inspirada en la Historiografía Marxista Británica.

\section{BIBLIOGRAFÍA}

Acuña, V. (1984). La huelga bananera. San José: CENAP-CEPAS. 
Acuña, V. (1985). Clases sociales y conflicto social en la economía cafetalera costarricense: productores contra beneficiadores 1921-1936. Revista de Historia, Número especial(Número especial ).

Acuña, V. (1986 a). Patrones del conflicto social en la economía cafetalera costarricense (19001948). Revista de Ciencias Sociales, marzo(31).

Acuña, V. (1986 b). Los orígenes de la clase obrera en Costa Rica: las huelgas de 1920 por la jornada de ocho horas. San José: CENAP-CEPAS.

Acuña, V. (1988). Vida cotidiana, condiciones de trabajo y organización sindical: el caso de los zapateros en Costa Rica (1934-1955). Revista de Historia, Número especial.

Acuña, V. (1996). La historia social de Costa Rica: balances y perspectivas. Revista de Historia, Número especial.

Cartledge, P. (2005). ¿Qué es la historia social ahora? En D. Cannadine (Ed.), ¿Qué es la historia ahora? Granada: Universidad de Granada.

Cerdas, J. (1994). Condiciones de vida de los trabajadores industriales de San José 1930-1960. (Tesis de Maestría en Historia). San José: Universidad de Costa Rica.

González, E. (1994). El estudio del café en la historiografía costarricense de los últimos diez años (1984-1994): un balance. Revista de Historia(30 jul-dic).

Hernández, C. (1996). Fases y tendencias de cambio en los estudios sobre la clase trabajadora costarricense: un balance historiográfico. Revista de Historia, Número especial.

Hobsbawn, E. (2011). Cómo cambiar el mundo. Marx y el marxismo 1840-2011. Barcelona: Crítica.

Kaye, H. (1989). Los historiadores marxistas británicos. Un análisis introductorio . Zaragoza: Universidad de Zaragoza.

Mora, V. (1992). Mujer e historia: la obrera urbana en Costa Rica (1892-1930) (Tesis de Licenciatura en Historia). San José: Universidad de Costa Rica.

Mora, V. (1998). Rompiendo mitos y forjando historia. Mujeres urbanas y relaciones de género en el San José de los años 20. (Tesis de Maestría en Historia). San José: Universidad de Costa Rica.

Morris, R.J. Class and class consciousness in the Industrial Revolution 1780-1850. Lecture in Economic History, University of Edinburg; 1990.

Murillo, C. (1995). Identidades de hierro y humo: la construcción del ferrocarril al Atlántico 18701890. San José: Porvenir.

Rojas, F. (2004). Historia económica y social de los carpinteros y ebanistas en el Valle Central de Costa Rica. De la colonia a 1943 (Tesis de Maestría en Historia). San José: Universidad de Costa Rica.

Rosabal, G. (1998). El mundo del trabajo y la dinámica social en la producción de pan en Costa Rica, 1900-1950 (Tesis de Maestría en Historia). San José: Universidad de Costa Rica. 


\section{ACERCA EL AUTOR}

Francisco Javier Rojas Sandoval: Doctor en Historia por la Universidad de Costa Rica, profesor en la Escuela de Historia de esa casa de estudios e investigador del Centro de Investigaciones históricas de América Central. Correo electrónico: franco0888@hotmail.com 